\title{
An Emergent Framework of Disaster Risk Governance towards Innovating Coping Capability for Reducing Disaster Risks in Local Communities
}

\author{
Saburo Ikeda ${ }^{1,2, *}$ and Toshinari Nagasaka ${ }^{2}$ \\ ${ }^{1}$ Professor Emeritus, University of Tsukuba, Tsukuba 305-8577, Japan \\ ${ }^{2}$ National Institute for Earth Science and Disaster Prevention, Tsukuba 305-0006, Japan
}

\begin{abstract}
An emergent framework of disaster risk governance is presented as an implementation strategy for integrated risk management that incorporates innovative local coping capabilities that reduce disaster vulnerability. This framework calls for enhancement of self-support and mutualassistance through strengthening informal or social networking efforts in local communities, rather than depending on formal or institutional governmental-assistance. The framework is supported by a societal platform of disaster risk information, called DRIP, which the NIED (National Research Institute for Earth Science and Disaster Prevention, Japan) has developed since 2006 as a tool that promotes improved disaster risk governance. With the help of DRIP, residents, communities, and other stakeholders, linked horizontally or vertically with social networks, can (1) improve their awareness of disaster risks and management issues by sharing risk information as scientific expertise, experiential knowledge, and local/folk wisdom; (2) customize risk communication through analytic deliberation of risk information by employing risk-scenarios developed by residents themselves; (3) develop collaborative activities for informed decision-making that can fully utilize local resources to reorganize coping capability against disaster risks; and (4) disseminate the generated risk scenarios with action plans to other residents who have not participated in the risk communication process.
\end{abstract}

Keywords disaster coping capability, risk communication, risk governance, risk scenario, social networks

\section{Introduction}

A multitude of structural changes have occurred in postindustrial society. Rapid urbanization, aging populations with low-birth-rate, mobilized employment, sociocultural changes in life-style as well as in emergence of a working-style with long commuting time, and defective housing in densely built-up areas are just a few of the developments that have created the disaster risks far more complex and uncertain than ever before. In Japan, two recent disaster experiences have

\footnotetext{
* Corresponding author. E-mail: saburo_ikeda@nifty.com
}

had an extraordinary impact: (1) the 1995 Hanshin-Awaji Earthquake of magnitude 7.3, which caused over six thousand deaths and property damage of ten trillion yen (about 110 billion U.S. dollars); and (2) the 2011 East Japan Earthquake of magnitude 9.0 along with the giant tsunami it triggered, which devastated not only most of the northeastern coastal regions in the main island of Japan with twenty thousand fatalities, but also brought a massive scale of radioactive fallout from the induced nuclear accident of Fukushima Dai-ichi Nuclear Power Plant (International Atomic Energy Agency's level 7 event, a very serious accident indeed). These catastrophic events demonstrated that people in the street face a number of multiple risks that originate from both natural and technological hazards. Although Japan's legal and institutional framework for disaster risk management has considerably improved, local ability to cope with socially and technologically induced disaster risks needs to be reorganized so as to deal with uncertain risks beyond the scope of the risk scenarios calculated by experts (Ikeda 2011).

How to cope with such complex and multiple risks in terms of health, safety, and environmental issues become salient themes for research institutions in both the natural and social sciences. During the 1990s, researchers and experts in riskrelated disciplines such as risk analysis, public health, safety and disaster sciences, insurance, sociology, and so on started to expand their analytical frameworks in order to respond to a growing demand for better policy making in a highly complex and uncertain world. Some sociologists, such as Beck (1992) and Giddens (1999), argued that socioculturally constructed risks could be driving forces initiating the reorganization of the structural and functional relationships in the post-industrial society. In this context, informed decision making on the allocation of society's risk burden could be critical in both a personalized and globalized world called the "risk society."

In the field of technological risk management, the IRGC (International Risk Governance Council) proposed a framework for risk governance that provided guidelines on integrated strategies for managing sociotechnological risks in 
a highly complex and uncertain risk environment (IRGC 2003). This framework requires specific consideration of stakeholders' participation in informed decision making that focuses on the relationship between risks and benefits, and identifies tradeoffs between different risks in terms of social context and risk reduction options. In the field of public policy, the producers and providers of public services become more diversified due to structural change in most of postindustrial society. Hence, policy implementation by government organizations has been directed to the formation of public service networks and their appropriate management by associated NPOs (Non-Profit Organizations) or parastatial corporations, with the aim of more accurately achieving public policy objectives. This trend from traditional government to governance with stakeholder participation and networking in all implementation processes leads necessarily to an important question: how effective are such approaches in forming social networks as well as in promoting informed decision making among the stakeholders under complex and uncertain risk conditions (McDaniels and Small 2004; Goldsmith and Eggers 2004; Lyall and Tait 2005).

The recent development of risk governance is one such outcome by which to cope with the risk issues under high uncertainty, complexity, and ambiguity in regulatory or management processes (Renn 2008). Since then, the term "risk governance" has prevailed in a wide range of disciplinary perspectives including in fields such as public administration, international economics and trade, environmental policy, urban and community policy including disaster prevention and crisis management among others. In those policy areas where the term "risk governance" is used, we can see some of the common features that characterize the nature of risk governance such as collaboration and coordination among a wide range of stakeholders, collective informed decision making, open and bottom-up consensus building, social networking, openness and accountability, and similar traits.

This article consists of three parts. The first part is concerned with an emergent framework of disaster risk governance evolved from the conventional framework of risk management, bearing in mind the recent development of integrated approach to disaster risk management since the year of international strategy for disaster reduction, 2000. Our framework of disaster risk governance will be presented in the context of innovating coping capacity against disaster vulnerability in the local communities, focusing primarily informed decision making among residents and other stakeholders on how to utilize effectively local resources in terms of reducing disaster risks up to the acceptable level of damages.

The second part is concerned with the methods and tools employed to implement disaster risk governance that have been developed by NIED (National Research Institute of Earth Science and Disaster Prevention, Japan) since the beginning of the second stage of the project in 2006. A scenario-based disaster risk communication is one of the core implementation methods by which residents and other stakeholders recognize a need to develop innovative governance structures. It is a specific type of risk communication methodology intended to promote collaboration among stakeholders by discovering and utilizing the local resources needed for reducing disaster risks. In addition, the methodology provides several tools of ICT (Information and Communication Technology) to facilitate networking among residents and their organizations both inside and outside the community (Nagasaka 2006).

In the final part, the outcomes of case studies that evaluate the effect of scenario-based risk communication conducted in several communities in urban and rural areas in Japan are discussed. The evacuation shelter operations are used as a typical example of disaster risk governance because such operations require a considerable degree of deliberative collaboration among residents and other stakeholders (local government, disaster-prevention NPOs, business groups, and so on). Many normally unseen or unexpected risk issues may suddenly emerge as extraordinary events depending on the different context in local communities. This creates an opportunity for participants to find out how to reorganize the disaster risk governance structure in their local communities.

\section{Risk Governance in the Context of Innovating Disaster Coping Capability}

\subsection{From Traditional Risk Management to Risk Governance}

In recent years, disaster prevention policies in most of industrialized countries have been directed to systematization of risk management functions in an integrated way that strengthens comprehensive prevention policy and diversified measures among various regulatory actors and organizations. For example, the ISDR (International Strategy for Disaster Reduction), created in 2000 after the 1995 Hanshin-Awaji Earthquake, stressed that it is "systematic efforts of analyzing the causal factors of disasters which includes exposure to hazards, lessening vulnerability of people and property, wise management of land and the environment, and improving preparedness for adverse events" (UNISDR 2010). As far as research on disaster risk management in Japan is concerned, DPRI (Disaster Prevention Research Institute, Kyoto University) and IIASA (International Institute for Applied Systems Analysis) initiated jointly the Integrated Disaster Risk Management Project in 2001 (Amendola et al. 2008). In the same year, NIED also began a project Social Systems Resilient to Disasters to explore various integrative approaches to risk management based on case studies in local communities in order to reorganize coping capability against disaster risk in Japan (Ikeda, Sato, and Fukuzono 2008). Various types of integrated management approaches and tools of communicating risks among stakeholders were developed to support the 
improvement of the residents' understanding of risk information about such issues as the nature of disaster risk, the content of hazard maps, types of disaster insurance, measures and routes of evacuation, and other countermeasures to respond in advance to risks (Ammann 2006; Alexander 2006; Ikeda 2006).

\subsection{An Emergent Framework of Disaster Risk Governance}

Having had such development of integrated approach to disaster risk management, disaster risk governance can be defined as an emergent version of integrated risk management that is tailored or directed to enhancing coping capacity under the high complexity and uncertainty conditions of postindustrial society. A multitude of collaborations, interactions or decision making actions are carried out by a wide range of stakeholder participants (national/local governments, local communities, residents groups, business groups, and NPOs). These interactions operate through various types of multifaceted networks and organizations with which most of the stakeholders are vertically or horizontally associated. These networks and organizations do not necessarily engage in formal or institutional coordination. Rather they work mostly as informal or noninstitutional interactions in both vertical and horizontal ways, while each maintains its independence and uniqueness (Nagasaka and Ikeda 2008).

Coping capacity is generally considered to be one of the key elements of vulnerability associated with a degree of exposure to hazards or a degree of being damaged by disasters, depending largely on physical and sociocultural environments in terms of utilizing in combination all of the strengths and resources available within the management sphere to reduce the level of risk (Alexander 2000; Birkmann 2006). In our framework of risk governance, we consider that this coping capacity consists of both revealed (direct) and latent (indirect) capacity depending on institutional structure of risk management and sociocultural networking in local communities. Revealed capability corresponds to formal and public countermeasures, which involve infrastructure and services for disaster prevention such as structural facilities of disaster prevention, evacuation shelters, fire brigades, and monitoring/warning systems. Latent capability refers to a community's or residents' potential to cope with disaster risks that are primarily cultivated through their daily activities. But these capabilities might emerge as self- or mutual-assistance practices under emergency situations. This is similar to social capital, but more concrete and practical in terms of providing opportunities for residents and other stakeholders to take part in activities that might raise locally shared risk awareness within the communities (Nagamatsu et al. 2008).

The key question is how to integrate both capabilities to strengthen total coping capacity in disaster risk governance. We maintain that it is latent capability that plays such a critical role in revitalizing revealed coping capacity so it works adequately in cases of unexpected disasters beyond the scope of the estimated risks analysis of expert or experiential knowledge. The more aware local residents are of the disaster risk, the greater is the revealed capacity of the community.

\section{Methods and Tools for Implementing Disaster Risk Governance}

\subsection{Disaster Risk Information Platform}

In the second stage of the NIED project (2006-2010), we have developed several methods and tools for supporting the implementation of disaster risk governance (NIED 2010). Both the Disaster Risk Information Platform (DRIP) and scenario-based disaster risk communication are principal instruments in conducting case studies in local communities in Japan (Usuda et al. 2008). As illustrated in Figure 1, DRIP is a societal platform of disaster risk information that works as a clearinghouse, collecting and disseminating scientific expertise in risk information from various disaster prevention organizations, fire brigades, and research institutions. DRIP also passes on local and experiential information from residents and civic organizations under interoperable environments linked by multilayered networks. In addition, as an affiliated system to DRIP, an "e-community system" has been developed that works as a portal site to DRIP and uses the internet to extend the capacity of the traditional community primarily in terms of facilitating proactive sociocultural networking inside and outside of local communities. This e-community system is composed of a web-log system and a GIS (Geographic Information System), and serves as a tool by which to conduct scenario-based risk communication. As illustrated in the lower part of Figure 1, local residents and other stakeholders in communities can use this e-community system from their browser or cell phones not only to enhance their knowledge of disaster risks and previous disaster experiences, but also to share the information of early warnings or evacuation alarms at their locations or in their meetings so that they are able to undertake immediate collaborative action.

\subsection{Method of Scenario-Based Risk Communication}

With the aid of DRIP, together with the e-community system, a series of workshops using scenario-based risk communication can be organized in local communities with a broad array of participant stakeholders who are willing to participate primarily from local networks connected in multilayered way inside and outside of local communities beyond their administrative boundary. The process of scenario-based risk communication includes: (1) identifying hazards, assessing risks, and evaluating possible damage in terms of exposure and vulnerability of local communities to specific disasters; (2) generating action plans as collaborative risk reduction activities with possible innovation of traditional revealed coping capability to achieve the full use of local resources; 


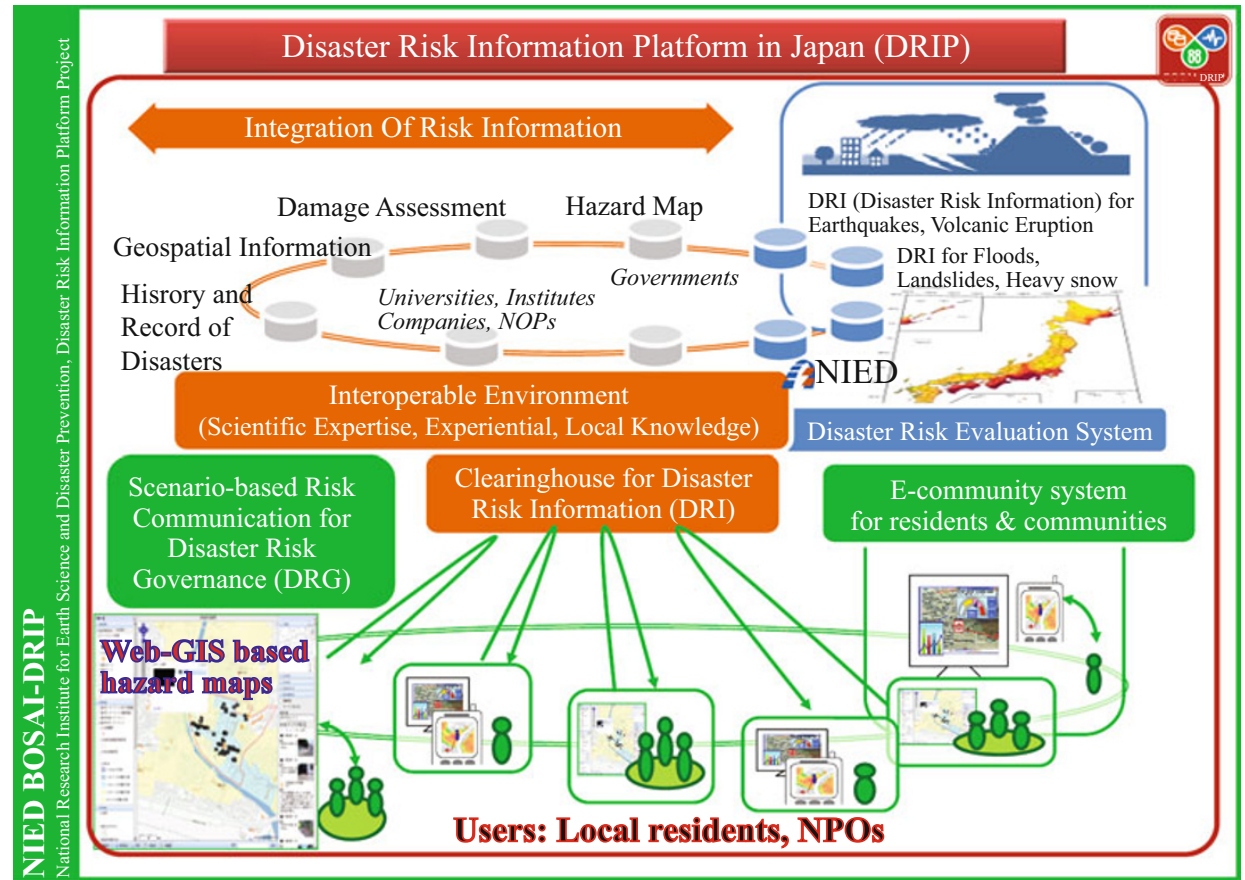

Figure 1. Schematic illustration of relationships between DRIP and scenario-based risk communication or e-community system

Source: NIED 2010.

and (3) disseminating the generated risk scenarios to residents who have not participated in the communication activities. The overall process of scenario-based risk communication is shown in Figure 2 in relation to both revealed and latent coping capability, together with the societal platform of disaster risk information (DRIP). This is a specific type of risk communication method tailored to a particular regional/local context. Its purpose is not only to promote a basic understanding of disaster risks, but also to allow concerned parties to make informed choices about possible action plans for reorganizing the governance structure in their communities.

\section{Case Studies on Implementing Disaster Risk Governance}

\subsection{Workshop Designs for Evacuation Shelter Operations}

A series of workshops in cooperation with the residents, local governments, and members of the NGOs (Non-Government Organizations) were conducted at more than twenty communities in such typical urban or suburban cities as Fujisawa City of Kanagawa Prefecture, Shimada City of Shizuoka Prefecture, Tsukuba City of Ibaraki Prefecture, and rural community of Yamakoshi District of Niigata Prefecture in Japan, facing the uncertain risk of catastrophic or multiple types of disasters during the period between 2006-2011. Detailed documents on the workshops can be found in
Japanese at NIED's Web Site (NIED 2011). Among the various issues of disaster risk management, evacuation shelter operation was one of the most frequently discussed themes in most of the case studies. In fact, a full range of unexpected risk issues may suddenly emerge as extraordinary events during the shelter operations depending on different types and impacts of disasters. Twenty-seven management issues were identified from the time a shelter is established until its closure based on the lessons and experiences learned from the past disasters (Tsubokawa, Nagasaka, and Usuda 2008).

Here we present a detailed program of the workshops held in Fujisawa City as a typical case for reorganizing the disaster risk governance structure at the level of communities. Fujisawa City has a population of about 400,000 . It is a typical bedroom town in the Tokyo area, where the older generation has memories of the Great Kanto Earthquake of 1923. In July 2008, we held a series of scenario-based risk communication workshops focusing on evacuation shelter management issues at Kugenuma Junior High School. In this district, a group of nine resident-neighborhood associations has established a local council for disaster prevention and they have designated this school as their evacuation shelter.

For the workshop at Kugenuma District of Fujisawa City, eight issues were selected for a one-day program starting at 10 a.m. and ending at 4 p.m. For this task, it is assumed that an earthquake of seismic intensity 6 occurred during a winter evening and caused a large-scale power failure in this community (Kugenuma District of Fujisawa City). In addition, prior to the workshop, the participants learned about the 


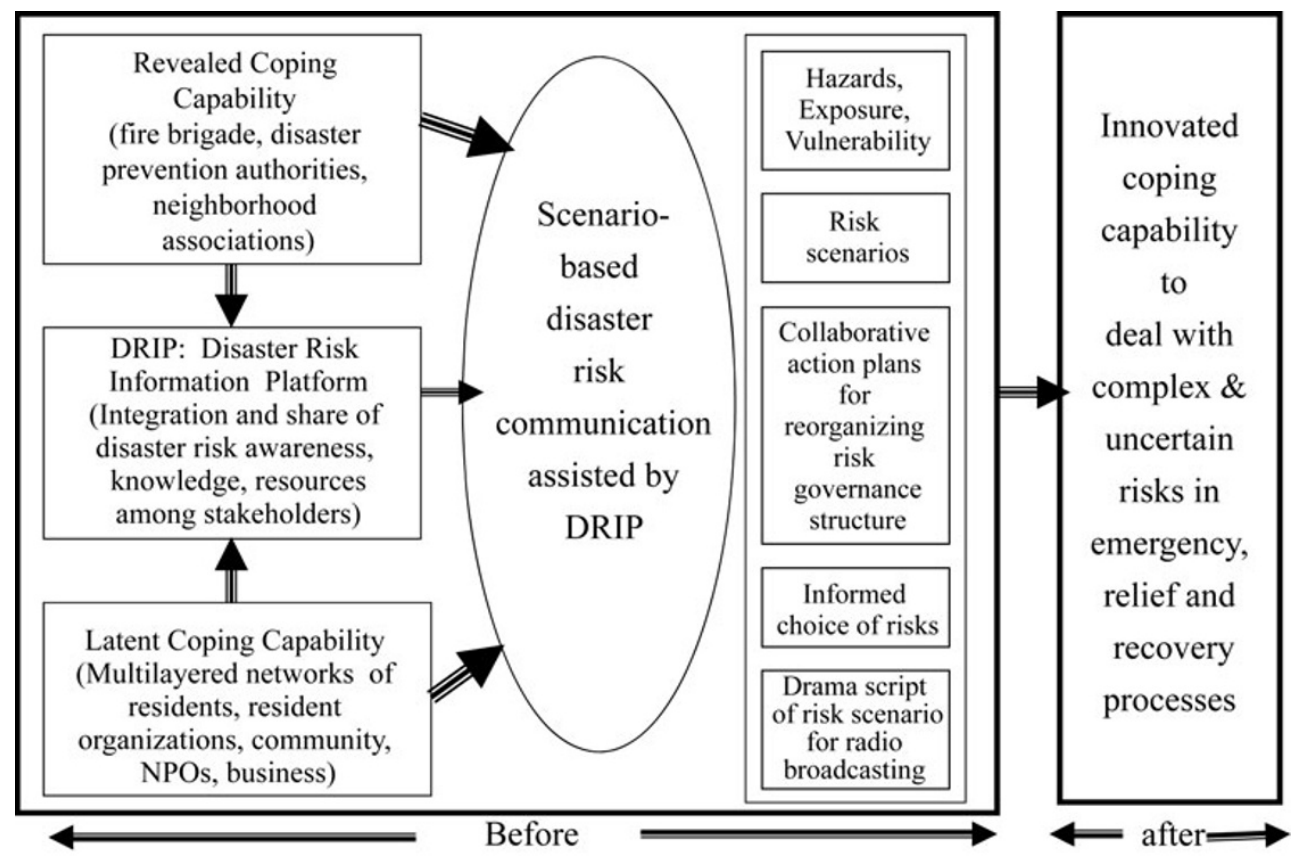

Figure 2. Overall process of scenario-based risk communication for innovating coping capability to deal with complex and uncertain disaster risks

disaster risks in terms of hazards, exposure, and vulnerability in their area and the various parties (stakeholders) involved in the evacuation shelter operation by getting a sort of integrated risk knowledge from the DRIP.

The first task of the workshop was to follow standard formal evacuation procedure, and then confirm that the school building was structurally safe for use as an evacuation shelter before earthquake evacuees can move into the facility. Figure 3 illustrates an overall program of the workshop as to evacuation shelter operation from the proactive participation up to dissemination of the output.

\subsection{Disaster Risk Scenarios with Role Playing}

Disaster risk scenarios are chronological descriptions of how uncertain events that are more or less related to a sequence of possible hazards can happen. According to recent studies in the cognitive sciences, awareness and understanding of the nature of disaster risks are enhanced when the risks are expressed in the narrative form of risk scenarios or past experiences rather than in the scientific form of risk information, such as the numbers of fatalities, injuries, houses and buildings destroyed, and fires (Schank 1990). The risk scenarios are produced at workshops attended by local residents who share their disaster awareness either in terms of past experience or virtual reality learned from various sources such as the scientific or experiential risk information arranged on GIS maps that are to be edited by the e-community system and the DRIP. In the method of scenario-based risk communication, the generated risk-scenarios are recorded in the form of a movie or play script that reflects the discussions among the participants, who act as stakeholders in shelter operation in a similar manner to engaging in role-playing games. In addition to playing ordinary evacuees, the participants also were asked to play the roles of various people associated with shelter's activities such as the school official managing the evacuation shelter (generally the school principal), representatives of resident organizations or neighborhood associations, social workers, volunteers, local government staff, and local storeowners. This allowed them to speak more freely and develop ideas outside the official content of the operation manual prepared by the authorities. For example, they could discuss forming a group of volunteers that would provide support to neighborhood associations that have difficulty providing care for elderly persons who require nursing care or could verify the safety of residents outside the scope of predetermined operation activities.

\subsection{Compilation of Action Plans and Dissemination of the Output to Residents}

Proposed action plans for collaborative activities can be classified in various ways, such as by degree of collaboration among stakeholders (for example, residents, neighborhood associations, or government authorities) or by the amount of time needed to realize the plan (immediately, within one year, or over several years). In this article, we classify the plans using a three-cornered framework known as a stakeholder triangle (see Figure 3), inspired by the "welfare triangle" proposed by Pestoff (1998), with specific attention to the 


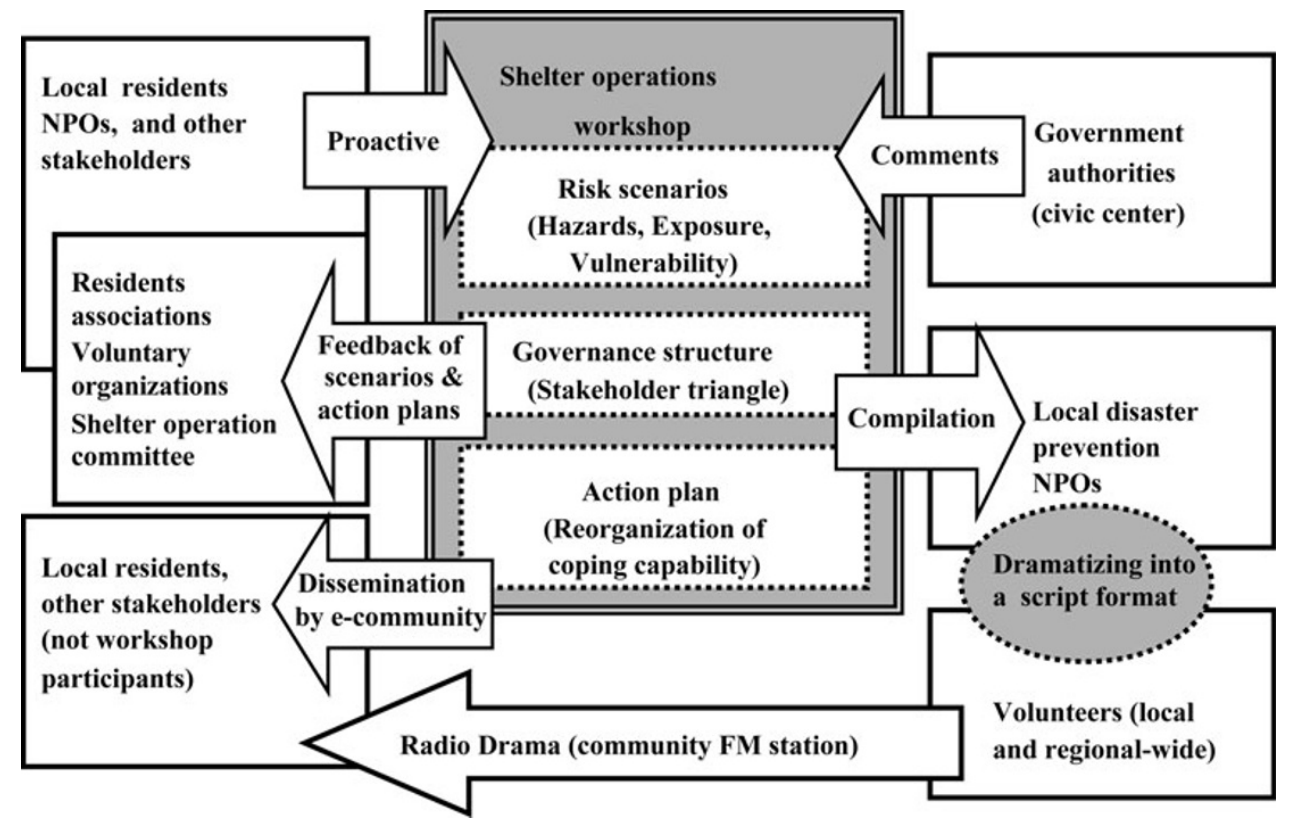

Figure 3. Overall scheme of workshop based on scenario-based risk communication

Source: Tsubokawa, Nagasaka, and Usuda 2008.

relationship between stakeholders in terms of three different types of organizational functions such as formal/informal, public/nonpublic, or profit/nonprofit with regard to a degree of possible collaboration. Then, the proposed action plans are placed in this stakeholder triangle (government authorities, community, and business and stores), depending on the degree of collaboration to which each stakeholder has responsibility (Defourny and Pestoff 2008). This framework makes it easy to compile action plans and understand the characteristics of the issues and specific actions from each stakeholder's perspective. Figure 4 is an example of such a compilation concerning the issue of verifying the safety of evacuation facilities. Two measures for solving this problem were proposed. The first one was based on the existing network between the community and government authorities, while the second one was based on the network between the community and businesses. Even though many of the participants were aware that the school (site of evacuation shelter) had already been renovated to improve earthquake resistance, they expressed psychological resistance to entering the building after an actual disaster, as on the assumption that the building might have been badly damaged. In this situation, from the standpoint of actively utilizing local resources to solve problems, the participants felt that someone with expert knowledge who lived in the area should be identified and registered in advance as the person or persons most capable of determining whether the school was safe to absorb evacuees.

The proposals generated at the workshop were recompiled as practical and feasible action plans by the volunteer organization for disaster prevention based in Fujisawa City (Tsubokawa, Tanaka, and Nagasaka 2008). Table 1 summarizes the recompiled action plans based on the required elements of disaster risk governance in the following four categories: integrating various types of knowledge, diversifying stakeholders, utilizing local resources, and reorganizing the roles of stakeholders in shelter operations as discussed in section 3 . Here we can see a set of action plans covering those four categories for better risk governance in Fujisawa area. In addition, a radio drama (see also Figure 3) of the disaster event was produced as a follow-up activity after the scenariobased risk communication. Some of the participants and volunteers were willing to take part in scripting and acting in the drama. This is a particularly effective way to disseminate the outcomes of the scenario-based workshop to wider audiences in the communities, either by broadcasting it on the community FM station or by distributing a CD of the recorded drama to local residents who did not participate at the workshops.

\subsection{Lessons from Other Case Studies}

In one of the activities associated with official disaster training in Shimada City of Shizuoka Prefecture, where the Tokai Megaquake of magnitude 8.0-8.5 is officially anticipated by government authorities with an 87 percent outbreak probability in the next 30 years (Japan Meteorological Agency 2011), a volunteer group of residents created its own hazard map by electronically superimposing official landslide hazard information on the official hazard map of seismic intensity with the help of Shimada's e-community system (see the lower right corner of Figure 1). Although this new hazard map was generated as a virtual reality by E-Community Shimada, it worked efficiently as a coordination map that linked together volunteers and local residents in pursuit of a common goal: 


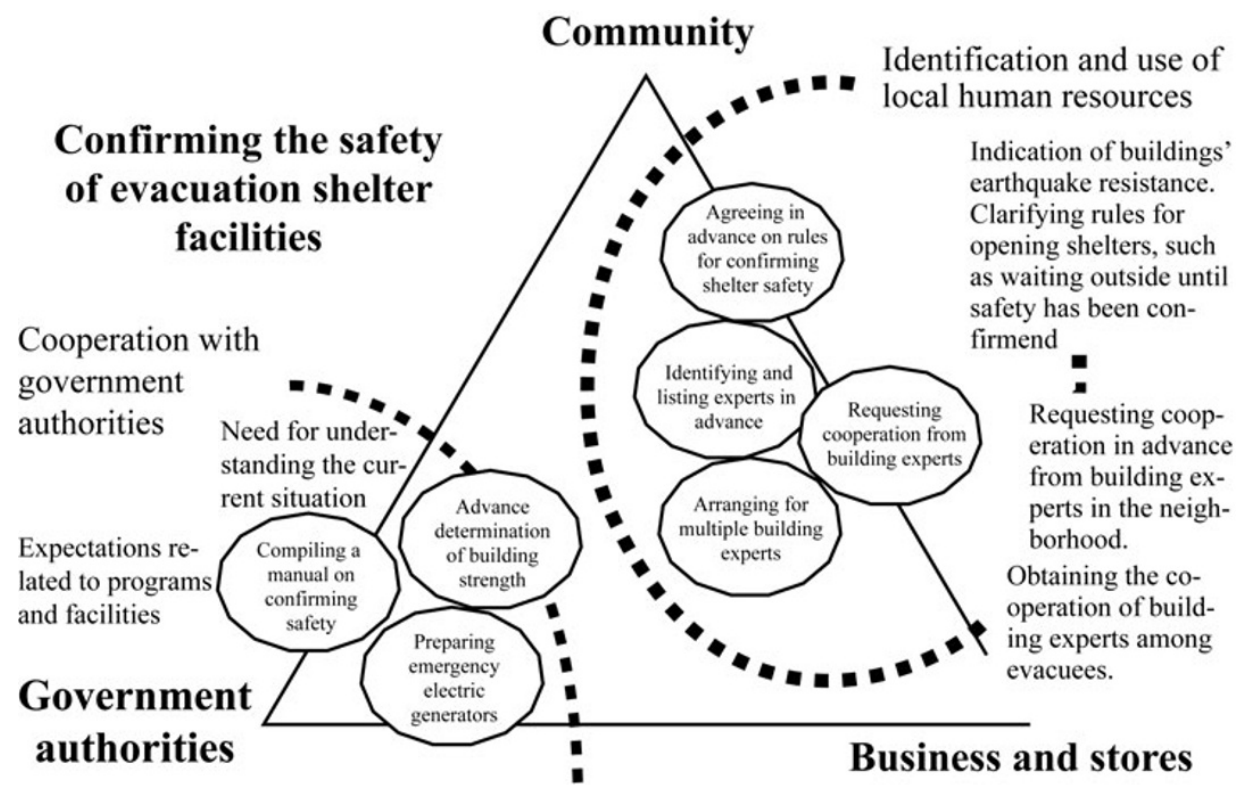

Figure 4. Example of action plan for verifying the safety of a facility as an emergency shelter

Source: Tsubokawa, Nagasaka, and Usuda 2008.

Table 1. Examples of action plans compiled at the workshop in terms of disaster risk governance

\begin{tabular}{|c|c|c|c|c|}
\hline Action plan & $\begin{array}{l}\text { Knowledge } \\
\text { integration }\end{array}$ & $\begin{array}{c}\text { Diversification of } \\
\text { stakeholders }\end{array}$ & $\begin{array}{l}\text { Use of local } \\
\text { resources }\end{array}$ & $\begin{array}{c}\text { Reorganization of } \\
\text { stakeholder roles }\end{array}$ \\
\hline $\begin{array}{l}\text { Identify local experts who will be needed } \\
\text { at times of disaster }\end{array}$ & & & O & O \\
\hline $\begin{array}{l}\text { Prepare manuals for confirming the safety } \\
\text { of school buildings }\end{array}$ & O & & & O \\
\hline $\begin{array}{l}\text { Hold training in the establishment of } \\
\text { evacuation shelters }\end{array}$ & & O & & \\
\hline $\begin{array}{l}\text { Study alternatives for buildings that may } \\
\text { become unfit for use in a disaster }\end{array}$ & O & & O & \\
\hline $\begin{array}{l}\text { Methods to identify persons requiring } \\
\text { support and verify their safety }\end{array}$ & & O & & O \\
\hline $\begin{array}{l}\text { Secure space at evacuation shelters for } \\
\text { persons requiring support }\end{array}$ & O & & O & \\
\hline $\begin{array}{l}\text { Organize a system for utilizing disaster } \\
\text { volunteers }\end{array}$ & & O & & \\
\hline $\begin{array}{l}\text { Personal cards with information about } \\
\text { support needs }\end{array}$ & & O & & ○ \\
\hline Plans for the distribution of relief supplies & & & O & \\
\hline $\begin{array}{l}\text { Call on individuals to store supplies } \\
\text { themselves }\end{array}$ & & & & O \\
\hline $\begin{array}{l}\text { Cooperation with stores and businesses on } \\
\text { relief materials }\end{array}$ & & & O & O \\
\hline
\end{tabular}

Source: Tsubokawa, Nagasaka, and Usuda 2008.

finding critical places where landslides might be triggered by the Tokai Megaquake. This experience shows that the single content of landslide hazard information, which was prepared by one governmental authority, can be utilized in different perspectives by various stakeholders in local communities.
This grassroots planning process also created a variety of practical disaster prevention activities based on local networks that contributed to a reorganization of the local risk governance structure (Kawai, Masuda, and Hanashima 2008). 
Another instructive case is provided by Tsukuba City. Here the administrative authority assumed that two big earthquakes, the South Ibaraki Earthquake of magnitude 7.3 and an earthquake of magnitude 6.9 occurring directly beneath the city, were possible sometime in the future. The threat posed by these two potential earthquakes created an urgent need to foster proactive networking efforts to link a variety of residents and groups who were willing to participate in collaborative activities inside and outside their communities. Because of less definite information available on disaster risk, it was difficult for ordinary residents to develop a proper sense of the possible impact, on handicapped or aged people in particular that might be caused by such large-scale earthquakes (Masuda et al. 2007). From this point of view, a series of workshops were organized in cooperation with the Social Welfare Association in Tsukuba to generate disaster risk scenarios, including the type and scale of volunteer activities needed for handicapped and elderly people in case of an emergency. These activities were well organized by fully utilizing an e-community platform (E-Community Tsukuba). This informal structure was operated jointly by several of the volunteer groups rooted in Tsukuba, and was widely recognized by local authorities and community stakeholders. In this way, informal collaborative measures were requested by citizens that supported setting up satellites of the volunteer center in each community as well as establishing a training operation that dealt with shelter management issues associated with handicapped people in emergency situations (Lee, Tsubokawa, and Nagasaka 2011).

Throughout the cases of Fujisawa, Shimada, and Tsukuba, we have made a considerable effort to develop methodologies and tools for making a radio drama of disaster prevention activities based on the outcomes of the scenario-based risk communication as indicated in Figure 3. In order for the volunteer participants to dramatize the risk scenarios, including transforming action plans into a script format or to play the scripted story on air, we prepared guidelines and tools to make the disaster drama easier during the case studies (NIED 2010). In most cases, the dramas were successfully produced and aired on local community FM radio stations. Both booklets and CDs that recorded the interplay of disaster risk scenarios were also used in homes, schools, and communities. In addition, the e-community platform has disseminated widely the recorded content of the drama to both residents and stakeholders who have shown less concern at participating in collaborative activities. These collective endeavors have provided opportunities for participants to learn about important governance issues associated with disaster prevention activities in their communities.

\section{Concluding Remarks}

A framework for scenario-based disaster risk communication was developed for the residents and other stakeholders. The goal was to enhance understanding not only about the nature of disaster risks in a community, but also the need to improve that local community's risk governance structure. The framework focused on the policy issue of shifting from reliance on the traditional coping capability of disaster prevention institutions to enhancing the latent coping capability of multilayered networks linked with a broad range of stakeholders who shared common local resources in their communities.

Our case studies in Fujisawa and other cities in Japan revealed that when disaster risks are expressed both in the narrative form of risk scenarios assisted by scientific expertise and in local experiential knowledge provided by the societal platform of disaster risk information (DRIP), the residents' and other stakeholders' better understanding and awareness of disaster risks resulted in an improved structure of risk governance in their communities. Furthermore, the risk scenarios in narrative form can be more widely disseminated to local residents who did not participate in the workshop either by broadcasting the scripted drama from the risk scenarios or by distributing the compact disk recorded of the drama. We plan to further develop various approaches of disaster risk communication assisted by the DRIP in order to encourage local residents and communities to take deliberative collaboration for reducing disaster risks based on the increased coping capability linked to multilayered, interactive networks.

\section{Acknowledgments}

During the preparation of this paper, the authors received invaluable cooperation from other members of the project team working on the Disaster Risk Information Platform at the National Research Institute for Earth Science and Disaster Prevention, Japan. Although the views expressed in this paper depend on the joint efforts of all team members, final responsibility for their expression here lies with the authors.

\section{References}

Alexander, D. 2000. Confronting Catastrophe. Harpenden, UK: Terra Publishing.

. 2006. Crisis Intervention and Risk Reduction. In Coping with Risks due to Natural Hazards in the 21st Century, edited by W. J. Ammann, S. Dannenmann, and L. Vulliet, 51-56. London: Taylor \& Francis.

Amendola, A., J. Linnerooth-Bayer, N. Okada, and P. J. Shi. 2008. Towards Integrated Disaster Management: Case Studies and Trends from Asia. Natural Hazards 44 (2):163-68.

Ammann, W. J. 2006. Risk Concept, Integral Risk Management and Risk Governance. In Coping with Risks due to Natural Hazards in the 21st Century, edited by W. J. Ammann, S. Dannenmann, and L. Vulliet, 3-23. London: Taylor \& Francis.

Beck, U. 1992. Risk Society: Towards a New Modernity. London: Sage Publications.

Birkmann, J. 2006. Measuring Vulnerability to Promote DisasterResilient Societies: Conceptual Frameworks and Definitions. In Measuring Vulnerability to Natural Hazards, edited by J. Birkmann, 9-54. Tokyo: United Nations University Press. 
Defourny J., and V. Pestoff, eds. 2008. Images and Concepts of the Third Sector in Europe. WP No. 08/02. EMES European Research Network. http://www.emes.net/fileadmin/emes/PDF_files/Working Papers/WP_08_02_TS_FINAL_WEB.pdf.

Giddens, A. 1999. Runaway World: How Globalization is Reshaping Our Lives. London: Profile Books.

Goldsmith, S., and W. D. Eggers. 2004. Governing by Network: The New Shape of the Public Sector. Washington, DC: Brookings Institute Press.

Ikeda, S. 2006. An Integrated Risk Analysis Framework for Emerging Disaster Risks: Toward a Better Risk Management of Flood Disaster in Urban Communities. In A Better Integrated Management of Disaster Risks toward Resilient Society to Emerging Disaster Risks in Mega-Cities, edited by S. Ikeda, T. Fukuzono, and T. Sato, 1-22. Tokyo: TERRAPUB. http://www.terrapub.co.jp/e-library/nied/index. html.

—. 2011. Is "Beyond the Scope of the Risk-Scenario" out of the Framework of "Risk Analysis". Japanese Journal of Risk Analysis 21 (1): 1-5 (in Japanese).

Ikeda, S., T. Sato, and T. Fukuzono. 2008. Towards an Integrated Management Framework for Emerging Disaster Risks in Japan. Natural Hazards 44 (2): 267-80.

IRGC (International Risk Governance Council). 2003. White Paper on Risk Governance. http://www.irgc.org.

Japan Meteorological Agency. 2011. Prediction of the Tokai Earthquake. http://www.jma.go.jp/en/quake_tokai/.

Kawai, T., K. Masuda, and M. Hanashima. 2008. Significance and Problem of "E-Community Platform": Disaster Risk Communication. Japanese Journal of Risk Analysis 17 (3): 33-41 (in Japanese).

Lee, T., H. Tsubokawa, and T. Nagasaka. 2011. Re-Organizing of Local Disaster Prevention Capabilities through Scenario-Based Risk Communication: A Case Study of Tsukuba City in Japan. Proceedings of 3rd Global Disaster and Risk Conference, Davos.

Lyall, C., and J. Tait. 2005. New Modes of Governance. Hants, UK: Ashgate Publishing.

Masuda, K., T. Nagasaka, S. Nagamatsu, and Y. Usuda. 2007. Enhancement of Risk Governance by Introduction of E-Community Platform in Tsukuba City. Proceedings of SRA-Japan Annual Conference, Volume 20, Tokushima (in Japanese).
McDaniels, T., and M. Small. 2004. Risk Analysis and Society: An Interdisciplinary Characterization of the Field. Cambridge, UK: Cambridge University Press.

Nagamatsu, S., T. Nagasaka, Y. Usuda, and S. Ikeda. 2008. Measuring Disaster Coping Capacity of Local Communities for Better Risk Governance. Proceedings of 2nd Global Disaster and Risk Conference, Davos, 25-29 August 2008.

Nagasaka, T. 2006. New Mode of Risk Governance Enhanced by an E-Community Platform. In A Better Integrated Management of Disaster Risks toward Resilient Society to Emerging Disaster Risks in Mega-Cities, edited by S. Ikeda, T. Fukuzono, and T. Sato, 89-107. Tokyo: TERRAPUB. http://www.terrapub.co.jp/e-library/nied/index. html.

Nagasaka, T., and S. Ikeda. 2008. Strategy and Methodology for Disaster Risk Governance. Japanese Journal of Risk Analysis 17 (3): 13-23 (in Japanese).

NIED (National Research Institute for Earth Science and Disaster Prevention). 2010. http://risk.bosai.go.jp/ (in Japanese).

_. 2011. http://risk.bosai.go.jp/group.php?gid=1099/ (in Japanese).

Pestoff, V. A. 1998. Beyond the Market and State-Social Enterprise \& Civil Democracy in a Welfare Society. Aldershot: Ashgate Publishing.

Renn, O. 2008. Risk Governance: Coping with Uncertainty in a Complex World. London: Earthscan.

Schank, R. C. 1990. Tell me a Story: A New Look at Real and Artificial Memory. New York: John Brockman Associates Inc.

Tsubokawa, H., T. Nagasaka, and Y. Usuda. 2008. An Experiment on Evacuation Shelter Management Using Disaster Risk Scenario. Journal of the Institute of Social Safety Science 10: 511-19 (in Japanese).

Tsubokawa, H., M. Tanaka, and T. Nagasaka. 2008. Study of Risk Communication using Disaster Risk Scenarios-Case Study of an Earthquake Disaster Risk Scenario Making Conducted with Participation of Fujisawa City Residents. Journal of the Institute of Social Safety Science 17 (3): 43-53 (in Japanese).

UNISDR (United Nations International Strategy for Disaster Reduction). 2010. What is Disaster Risk Reduction? http://www.unisdr.org/ who-we-are/what-is-drr/.

Usuda, Y., T. Nagasaka, S. Okada, A. Amano, and H. Fujiwara. 2008. Disaster Risk Information Platform for Risk Governance. Proceedings of SRA-Japan Annual Conference, Volume 21, 1, Osaka (in Japanese).

Open Access This article is distributed under the terms of the Creative Commons Attribution License which permits any use, distribution, and reproduction in any medium, provided the original author(s) and source are credited. 